\title{
EDITORIAL
}

\section{O Ministério da Saúde e a Enfermagem}

Focalizamos, no número de dezembro de 1977, o papel do Ministério da Educação e Cultura no desenvolvimento da Enfermagem. Agora é o Ministério da Saúde (MS) que se faz notar por iniciativas recentes no mesmo sentido.

Referimo-nos a duas publicações de 1977 sobre trabalhos realizados conjuntamente por esse Ministério e pela Organização Panamericana da Saúde, da Organização Mundial da Saúde (OPAS-OMS).

A primeira, PADROES MINIMOS DE ASSISTENCIA DE ENFERMAGEM A COMUNIDADE, é o relatório de uma reunião de enfermeiras promovida pela Coordenadoria de Assistência Médica e Hospitalar da Secretaria Nacional de Ações Básicas de Saúde, com o propósito de "... servir de guia ao desenvolvimento do serviço de enfermagem..." Sua coordenação esteve a cargo do Setor de Enfermagem da Divisão Nacional de Organização Sanitária (DNOS) e de enfermeiras da OPAS-OMS. Dela participaram enfermeiras do MS, Ministério da Previdência Social, Secretaria de Saúde do Distrito Federal, de dois Territórios e de 16 Estados da Federação, de todas as macro-regiões do País.

O segundo, MODELO GERAL DE ENFERMAGEM, foi promovido pela mesma Seção de Enfermagem, com o propósito de "Capacitar o serviço de enfermagem, de âmbito estadual, para atuar como uma unidade de planejamento, coordenação e controle das ações de enfermagem nos níveis central, regional e local." Segundo o Diretor da 
DNOS, este trabalho constitui um modelo geral a ser adaptado pelas Secretarias de Saúde às suas peculiaridades locais.

Ambas as publicações são de utilidade inquestionável, principalmente em razão da desorientação das Secretarias de Saúde e dos respectivos serviços de enfermagem sobre a competência destes e as atividades do pessoal de enfermagem.

Confiantes na continuação desta política de atenção às necessidades dos serviços de enfermagem, esperamos ansiosamente o modelo geral de enfermagem hospitalar que se encontra em fase de elaboração.

Maria Rosa Sousa Pinheiro 